\title{
Cardiovascular Assessment of Patients with Ullrich-Turner's Syndrome on Doppler Echocardiography and Magnetic Resonance Imaging
}

\author{
Ana Valéria Barros de Castro, Katashi Okoshi, Sérgio Marrone Ribeiro, Mauríco Fregonesi Barbosa, \\ Patricia Ferreira Mattos, Ludiana Pagliare, Nancy Figueiredo Bueno, Débora Aparedida Rodrigueiro, \\ Adriana Lúda Mendes Haddad
}

Botucatu, SP - Brazil

\begin{abstract}
Objective - To assess the cardiovascular features of Ullrich-Turner's syndrome using echocardiography and magnetic resonance imaging, and to correlate them with the phenotype and karyotype of the patients. The diagnostic concordance between the 2 methods was also assessed.
\end{abstract}

Methods - Fifteen patients with the syndrome were assessed by echocardiography and magnetic resonance imaging (cardiac chambers, valves, and aorta). Their ages ranged from 10 to 28 (mean of 16.7) years. The karyotype was analyzed in 11 or 25 metaphases of peripheral blood lymphocytes, or both.

Results - The most common phenotypic changes were short stature and spontaneous absence of puberal development (100\%); 1 patient had a cardiac murmur. The karyotypes detected were as follows: $45, X(n=7)$, mosaics $(n=5)$, and deletions $(n=3)$. No echocardiographic changes were observed. In regard to magnetic resonance imaging, coarctation and dilation of the aorta were found in 1 patient, and isolated dilation of the aorta was found in 4 patients.

Conclusion - The frequencies of coarctation and dilation of the aorta detected on magnetic resonance imaging were similar to those reported in the literature (5.5\% to $20 \%$, and $6.3 \%$ to $29 \%$, respectively). This confirmed the adjuvant role of magnetic resonance imaging to Doppler echocardiography for diagnosing cardiovascular alterations in patients with Ullrich-Turner's syndrome.

Keywords: Doppler echocardiography, magnetic resonance imaging, Turner's syndrome

Faculdade de Medicina de Botucatu - UNESP

Mailing address: Ana Valéria Barros de Castro - Faculdade de Medicina de Botucatu Depto Clínica Médica - Distrito de Rubião Júnior, s/n - 18618-000 - Botucatu, SP, Brazil - E-mail: Ana.Castro@cshs.org

English version by Stela Maris C. e Gandour
Cardiovascular abnormalities were reported in $55 \%$ of patients with Ullrich-Turner's syndrome ${ }^{1,2}$, mainly coarctation of the aorta (5.5 to $20 \%$ ), aortic dilation (12.5 to $29 \%$ ), aortic aneurysm, and bicuspid aortic valve. Due to the great morbidity and mortality of the cardiovascular changes associated with Ullrich-Turner's syndrome, their early diagnosis is necessary ${ }^{1,2}$. Doppler echocardiography has been the most used complementary method for detecting them. However, the limitation of this method in assessing the thoracic aorta is well known ${ }^{2-4}$. In this regard, magnetic resonance imaging has the advantage of providing integral visualization of the thoracic aorta ${ }^{2,3}$.

The etiology of these abnormalities is unknown. Most of the time, the associations between karyotype and phenotypic characteristics, including cardiovascular alterations, are questionable ${ }^{5}$.

The objective of the present study was to assess cardiovascular alterations in patients with Ullrich-Turner's syndrome using Doppler echocardiography and thoracic magnetic resonance imaging, and to correlate their phenotypic and karyotypic characteristics, assessing concordance and discordance of the results with the 2 methods.

\section{Methods}

Fifteen patients with Ullrich-Turner's syndrome were assessed. Their ages ranged from 10 to 28 (mean of $16.7 \pm 4.0$ ) years. Six patients were being treated with growth hormone and 6 with estrogen. Written informed consent was obtained.

The karyotype was analyzed in 11 or 25 metaphases of peripheral lymphocytes ( $\mathrm{G}$ chromosome banding).

Doppler echocardiography was performed and analyzed by the same observer using the SONOS 2000 device (Hewlett-Packard Medical Systems, Andover, MA, USA). To measure the cardiovascular structures (left ventricular diastolic and systolic diameters, left ventricular wall thickness, and aortic root and left atrial diameters), a routine 
Doppler echocardiographic study was performed according to the recommendations of the American Society of Echocardiography ${ }^{6}$. We obtained images in the one-dimensional mode with the ultrasound beam oriented by the images in 2-dimensional mode, using the transducer of $3.5 \mathrm{MHz}$ in the short axis parasternal position. The 2-dimensional examination was also used for detecting congenital abnormalities of the heart. For flow analysis, we used the same transducer, operating at $2.7 \mathrm{MHz}$ of frequency.

Magnetic resonance imaging was performed with the General Electric-CGR device (MR MAX of 0.5 Tesla, France). Imaging of the cardiovascular structures was obtained coupled with the electrocardiogram using spinecho imaging sequences weighted in $\mathrm{T} 1$ with an echo time of $20 \mathrm{~ms}$ and repetition time determined by heart rate. To assess cardiac dimensions and ventricular wall thickness, we obtained images in the transverse and short cardiac axis planes, the latter perpendicular to the long cardiac axis. We also performed a sequence in the oblique sagittal plane, containing the ascending aorta, the aortic arch, and the descending aorta. The sections were $7-\mathrm{mm}$ thick by $10-\mathrm{mm}$ increment, and the measurements of the ascending and descending aorta were taken in the same plane in the axial sections, $1 \mathrm{~cm}$ above the aortic root, close to the emergence of the right pulmonary artery. The aortic dimensions were compared with the normal values for age. The expected values for the measurements of the ascending and descending segments were calculated based on the regression function established by Fitzgerald et al ${ }^{7}$ using cardiac computerized tomography. In the comparative analyses, in addition to the patient's chronologic age, we also considered the patient's statural age, which is the age corresponding to the patient's height assessed according to Marcondes et al ${ }^{8}$ height curves.

According to the results of magnetic resonance imaging, the patients were divided into the following groups: normal, aortic dilation, and coarctation of the aorta.

Statistical analysis was performed using Student $t$ test for unpaired sample, and Fisher exact test for comparing frequencies, considering $\mathrm{p}<0.05$ as significant.

\section{Results}

The patients had the following karyotypes: monosomy: 45,X-7 (46.7\%) patients; mosaicism: 45,X/46,XX-3 (20\%) patients; 45,X/46,X,r(X) - 1 (6.7\%) patient; 45,X/ 46,X,i(Xq)-1 (6.7\%) patient; deletions: 46,Xi(Xq)-2(13.2\%) patients; 46,X,Xp-,9qh+-1 (6.7\%) patient.

The most common phenotypic characteristics were low height and absence of spontaneous puberal development (100\%). The other phenotypic alterations according to magnetic resonance imaging are shown in table I.

No patient had cardiovascular disease on Doppler echocardiography (tab. II).

In a patient with 45 ,X karyotype and a normal echocardiogram, coarctation of the aorta with poststenotic dilation was detected on magnetic resonance imaging (fig. 1). Her clinical and imaging characteristics, compared with those of

\begin{tabular}{|c|c|c|c|}
\hline \multicolumn{4}{|c|}{$\begin{array}{l}\text { Table I - Phenotypic characteristics distribution according to the } \\
\text { aortic exam by magnetic resonance imaging }\end{array}$} \\
\hline Characteristics & $\begin{array}{l}\text { Normal } \\
(\mathrm{n}: 10)\end{array}$ & $\begin{array}{c}\text { Dilation } \\
(\mathrm{n}: 4)\end{array}$ & $\begin{array}{c}\text { Dilation } \\
\text { CoAo } \\
(\mathrm{n}: 1)\end{array}$ \\
\hline Age in years (mean $\pm \mathrm{SD})$ & $17.3 \pm 5.0$ & $13.8 \pm 3.3$ & 18 \\
\hline Weight in $\mathrm{kg}($ mean $\pm \mathrm{SD})$ & $41.8 \pm 7.7$ & $39.3 \pm 10.4$ & 27.6 \\
\hline Height in $\mathrm{cm}($ mean $\pm \mathrm{SD})$ & $111.2 \pm 58.4$ & $131.6 \pm 13.6$ & 125.6 \\
\hline Height Z - score & $-3.1 \pm 0.6$ & $-3.5 \pm 1.6$ & -6.1 \\
\hline Body surface area $\left(\mathrm{m}^{2}\right)$ & $1.23 \pm 0.2$ & $1.3 \pm 0.2$ & 0.95 \\
\hline Nevi (n) & 6 & 3 & Yes \\
\hline Ogival palate (n) & 4 & 3 & Yes \\
\hline Breast hypertelorism (n) & 3 & 3 & No \\
\hline Low posterior hairline (n) & 3 & 2 & No \\
\hline Short neck (n) & 2 & 1 & Yes \\
\hline Webbed neck (n) & 2 & 1 & No \\
\hline Cardiac murmur (n) & 0 & 0 & Yes \\
\hline Arterial hypertension (n) & 2 & 0 & Yes \\
\hline Hydronephrosis (n) & 1 & 0 & Yes \\
\hline Proteinuria (n) & 2 & 0 & Yes \\
\hline
\end{tabular}

\begin{tabular}{|lccc|}
\hline $\begin{array}{c}\text { Table II - Echocardiographic variables (mean } \pm \text { SD) } \\
\text { according to the aortic exam by magnetic resonance imaging }\end{array}$ \\
\hline Variables (cm) & $\begin{array}{c}\text { Normal } \\
\text { (n: } 10)\end{array}$ & $\begin{array}{c}\text { Dilation } \\
\text { (n: } 4)\end{array}$ & $\begin{array}{c}\text { Dilation/ } \\
\text { CoAo (n: } 1)\end{array}$ \\
\hline Aortic root diameter & $2.4 \pm 0.3$ & $2.4 \pm 0.3$ & 2.3 \\
LV (diastole) & $3.9 \pm 0.3$ & $4.2 \pm 0.2$ & 4.3 \\
LV thickness (diastole) & $0.7 \pm 0.1$ & $0.7 \pm 0.1$ & 0.7 \\
Left atrium (systole) & $3.0 \pm 0.2$ & $3.2 \pm 0.4$ & 3.0 \\
LV ejection fraction & $0.79 \pm 0.03$ & $0.79 \pm 0.07$ & 0.85 \\
\hline CoAo: coarctation of the aorta; LV: left ventricle; Valves: normal. \\
\hline
\end{tabular}

the remaining patients, are shown in tables I, II, and III. Clinically, this patient with coarctation of the aorta had a greater statural deviation as compared with the height expected for her age ( $\mathrm{z}$ score of -6.1 versus $-3.3 \pm 1.0)^{8}$ and a systolic murmur detected in the aortic area. The vascular alterations according to the karyotype are shown in table IV.

In regard to chronologic age, we observed that the measurements of the ascending and descending aortic segments in patients with Ullrich-Turner's syndrome on magnetic resonance imaging, and according to Fitzgerald et $\mathrm{al}^{7}$, were lower when compared with those of healthy children of the same age. However, when the statural ages of these children were considered, no significant differences were detected between the vascular measurements reported (tab. V).

According to the diagnostic criterion of aortic dilation on magnetic resonance imaging adopted in some studies ${ }^{2}$, ie, ascending aorta/descending aorta ratio $>1.5^{1}$, we observed isolated dilation of the ascending aorta in $4(26.7 \%)$ patients, of whom only 1 had the 45 ,X karyotype.

On magnetic resonance imaging, the patient with coarctation of the aorta had a reduced diameter of the descending aorta as compared with those of the patients who did not 


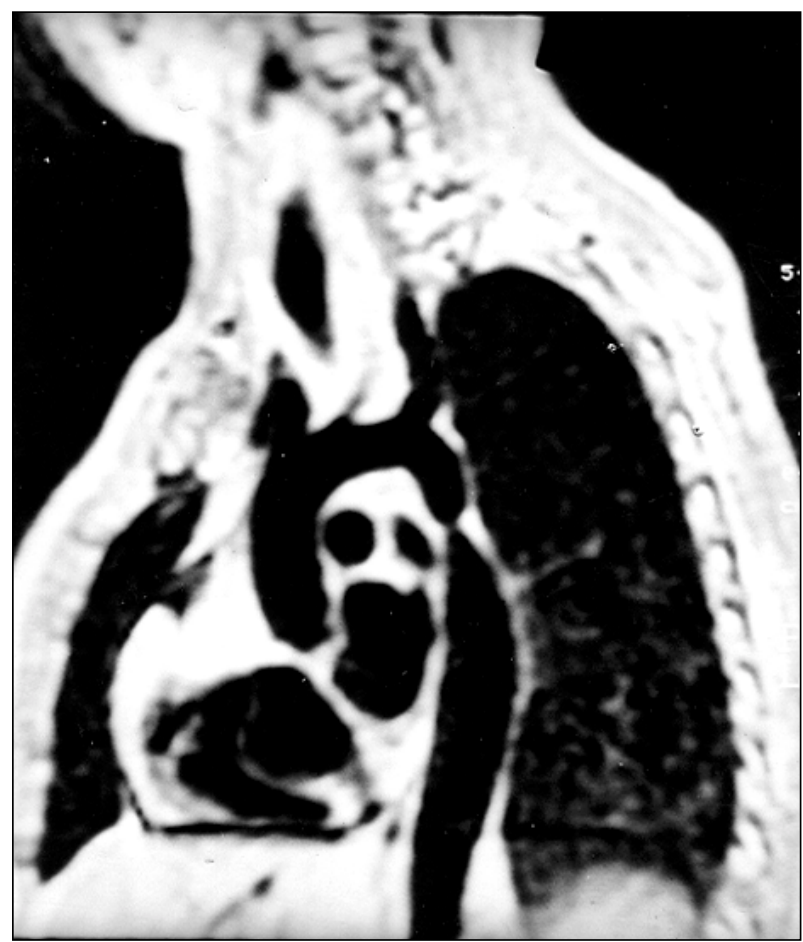

Fig. 1 - The descending aorta is dilated due to the post-stenotic dilation phenomenon.

\begin{tabular}{|c|c|c|c|}
\hline \multicolumn{4}{|c|}{$\begin{array}{l}\text { Table III - Aortic characteristics distribution (mean } \pm \text { SD) according } \\
\text { to the aortic exam by magnetic resonance imaging }\end{array}$} \\
\hline Aortic dimension $(\mathrm{cm})$ & Normal & Dilation & Dilation/CoAo \\
\hline Ascending Ao diameter & $2.2 \pm 0.3$ & $2.1 \pm 0.2$ & 2.0 \\
\hline Descending Ao diameter & $1.6 \pm 0.4$ & $1.3 \pm 0.2$ & 1.1 \\
\hline $\begin{array}{l}\text { Ascending Ao/ } \\
\text { descending Ao ratio }\end{array}$ & $1.40 \pm 0.10$ & $1.60 \pm 0.03$ & 1.81 \\
\hline
\end{tabular}

\begin{tabular}{|lcccc|}
\hline \multicolumn{5}{|c|}{$\begin{array}{c}\text { Tabela IV } \\
\text { - Karyotype distribution according to the aortic exam by } \\
\text { magnetic }\end{array}$} \\
\hline Karyotypenance imaging
\end{tabular}

\begin{tabular}{|c|c|c|c|}
\hline \multicolumn{4}{|c|}{$\begin{array}{c}\text { Table V - Comparison of ascending and descending aortic } \\
\text { diameters (mean } \pm \text { SD) versus reference values of chronologic and } \\
\text { statural ages }\end{array}$} \\
\hline \multirow[t]{2}{*}{ Aorta } & \multirow{2}{*}{$\begin{array}{l}\text { Diameter } \\
\quad(\mathrm{cm})\end{array}$} & \multicolumn{2}{|c|}{ Reference values } \\
\hline & & Chronologic age & Statural age \\
\hline Ascending & $2.1 \pm 0.3^{*}$ & $2.4 \pm 0.3$ & $2.0 \pm 0.1$ \\
\hline Descending & $1.5 \pm 0.3^{*}$ & $2.0 \pm 0.2$ & $1.5 \pm 0.1$ \\
\hline
\end{tabular}

have this alteration (tab. III). This was because the measurement was taken at the level of the coarctation in the proximal portion of the descending aorta. However, below this area of narrowing, the descending aorta was dilated as compared with the measurements of the other patients due to the phenomenon of poststenotic dilation (fig. 1).

The measures of the cardiac structures obtained on echocardiography are shown in table II.

In regard to the measurements performed with the aid of echocardiography and magnetic resonance imaging, we observed the following: no difference between the measures of the ascending aorta; no difference between the patients with 45,X karyotype and those with other karyotypes (mosaicisms and deletions); and no difference between the patients being treated or not with GH or estrogen, or both.

\section{Discussion}

Cardiovascular malformations are more frequently found in patients with Ullrich-Turner's syndrome than in the general population ${ }^{9}$. Factors linked to the $\mathrm{X}$ chromosome were considered involved in the pathogenesis of these malformations ${ }^{9}$. Patients with monosomy of the X chromosome usually have more severe cardiovascular alterations and more significant signs of dysmorphism ${ }^{9,10}$. However, according to other author's and our observations (tab. IV), the association of the severity of the chromosomal elimination and the presence of significant dysmorphisms, such as the presence of cardiovascular malformations, does not occur in all patients with Ullrich-Turner's syndrome ${ }^{5}$. This discrepancy between the observations may partially be due to the presence of hidden mosaicisms that are not diagnosed on usual karyotypic analyses in some patients with $45, X$ karyotype ${ }^{5}$.

Of the phenotypic characteristics, the webbed neck was more frequently associated with the presence of cardiovascular malformations, mainly coarctation of the aorta ${ }^{1,5,11}$. A pathogenic relation between them was suggested: the webbed neck resulting from cystic hygroma secondary to lymphatic obstruction would cause hemodynamic disarrangement and cardiovascular morphological alterations ${ }^{11,12}$. However, in our case series, this association was not observed, suggesting that other pathogenic mechanisms may be involved in the development of cardiovascular malformations in patients with Ullrich-Turner's syndrome. However, the analysis of a greater number of patients is required for definitive conclusions.

The diagnostic method frequently used for detecting cardiovascular malformations is Doppler echocardiography ${ }^{2}$. However, magnetic resonance imaging provides advantages in assessing the thoracic aorta ${ }^{2-4}$. A prospective study comparing results of Doppler echocardiography and magnetic resonance imaging revealed that $3 / 5$ of the patients with coarctation of the aorta and $4 / 5$ of the patients with dilation of the ascending aorta were detected only on magnetic resonance imaging ${ }^{2}$. Confirming these results, in our study, the most frequently observed cardiovascular alteration was dilation of the aorta (6/15 patients), isolated or associated with coarctation of the aorta ( $1 / 6$ patients), and it was detected only on magnetic resonance imaging. 
Little is known about the natural evolution of dilation of the aorta in patients with Ullrich-Turner's syndrome. In these patients, an association with the risk factors for dissection of the aorta, such as arterial hypertension, bicuspid aortic valve, and coarctation of the aorta, has been frequently observed, and suggests their lethal potential ${ }^{1,13}$. However, their detection depends on the criteria and diagnostic methods used.

According to the criteria of Rogé et al ${ }^{14}$, aortic root measures greater than the $90^{\text {th }}$ percentile in relation to body surface are diagnostic of dilation of that aortic segment. Using this criterion, the aortic root measures obtained in this study are within the expected values (tab. II).

The references for interpreting the measures of the aortic segments using magnetic resonance imaging are the same as those used in cardiac computerized tomography, and they vary according to chronologic age ${ }^{2}$. However, in children in the growth phase, the best variable to correlate with aortic measures is height ${ }^{15}$. If only the chronologic age was considered for determining the reference values, short-statured individuals, such as those with Ullrich-Turner's syndrome, would have overestimated reference measures of the aorta (tab. V), because the aortic measure also depends on the patient's height ${ }^{16}$. However, when we considered the statural age instead of the chronologic age, ie, age corresponding to height, these values were corrected and no alteration in the aortic diameter was observed (tab. V).

In another study ${ }^{2}$, using thoracic magnetic resonance imaging in patients with Ullrich-Turner's syndrome, the authors considered the presence of aortic dilatation when the ratio between the aortic root and the ascending aorta was greater than 1.5. According to this criterion, we observed that $4(26.7 \%)$ patients had dilatation of the aorta, corroborating the frequency reported in the literature (6.3 to $29 \%$ ).

In a European study, the prevalence of coarctation of the aorta was $0.32 / 1000$ in live newborn infants ${ }^{17}$. In regard to the patients with Ullrich-Turner's syndrome, the frequency of coarctation of the aorta reported ranged from 5\% to $20 \%^{1,2}$. In our case series, we detected only 1 patient $(1 / 15$ patient) with coarctation of the aorta. The variability of the frequency of coarctation of the aorta found in the literature depended on the diagnostic methods used and on how the patients with Ullrich-Turner's syndrome were selected. Lin et al ${ }^{13}$ reported a $42 \%$ frequency in this alteration in a study resulting from information provided by members of the Turner's Syndrome Society about cardiac abnormalities in patients with this syndrome. The presence of coarctation of the aorta was more frequently detected on magnetic resonance imaging $(12.5 \%)$ than on Doppler echocardiography $(5.5 \%)^{2,16,18}$, in accordance with our findings, and it occurred among the patients referred due to heart disease, and not only for screening of cardiovascular malformations, as in the present study.

In conclusion, considering the great morbidity and mortality of the cardiovascular alterations, mainly aortic, associated with Ullrich-Turner's syndrome, and the superiority of magnetic resonance imaging for detecting these alterations, this method should be used as an adjuvant to Doppler echocardiography in assessing these patients. However, criteria for assessing aortic measures and their reference values (site, section plane and thickness, phase of the cardiac cycle assessed) should be established for using these imaging methods ${ }^{5}$, to better evaluate cardiovascular alterations in patients with Ullrich-Turner's syndrome.

\section{Acknowledgments}

We thank Drs. Celia Regina Nogueira, Glaucia M.F. S. Mazeto, and Walkyria de Paula Pimenta for their support.

\section{References}

1. Lin AE, Lippe BM, Geffner ME, et al. Aortic dilation, dissection, and rupture in patients with Turner syndrome. J Pediatr 1986; 109: 820-6.

2. Dawson-Falk KL, Wright AM, Bakker B, Pitlick PT, Rosenfeld RG. Cardiovascular evaluation in Turner syndrome: utility of MR imaging. Austral Radiol 1992; 36: 204-9.

3. Fletcher BD, Jacobstein MD. MRI of congenital abnormalities of the great arteries. Am J Radiol 1986; 146: 941-8.

4. Gomes AS, Lois JF, George B, Alpan G, Williams R. Congenital abnormalities of the aortic arch: MR imaging. Radiology 1987; 165: 691-5.

5. Lippe B. Turner Sydrome. In: Sperling MA, Pediatric Endocrinology, WB Saunders: Philadelphia, 1996: 387-421.

6. Sahn DJ, Demaria A, Kisslo J, Weyman AE. The Committee on M-Mode Standardization of the American Society of Echocardiography. Recommendations regarding quantitation in M-mode echocardiography: results of a survey of echocardiographic measurements. Circulation 1978; 58: 1072-83.

7. Fitzgerald SW, Donaldson JS, Poznanski AK. Pediatric thoracic aorta: normal measurements determined with CT. Radiology 1987; 165: 667-9.

8. Marcondes E, Berquó E, Hegg R, Colli A, Zacchi MAS. Crescimento e desenvolvimento pubertário em crianças e adolescentes brasileiros. 1. Metodologia. São Paulo: Ed. Brasileira de Ciências, 1982.

9. Mazzanti L, Cacciari E. Congenital heart disease in patients with Turner's syndrome. Italian Study Group for Turner Syndrome (ISGTS). J Pediatr 1998; 133: 688-92.

10. Prandstraller D, Mazzanti L, Picchio FM, et al. Turner's syndrome: cardiologic profile according to the different chromosomal patterns and long-term clinical follow-up of 136 nonpreselected patients. Ped Cardiol 1999; 20: 108-12.

11. Clark EB. Neck web and congenital heart defects: a pathogenic association in 45,X-O Turner Syndrome? Teratology 1984; 29: 355-61.

12. Allen DB, Hendricks AS, Levy JM. Aortic dilation in Turner syndrome. J Pediatr 1986; 109: 302-5.

13. Lin AE, Lippe B, Rosenfeld RG. Further delineation of aortic dilation, dissection and rupture in patients with Turner syndrome. Pediatrics 1998; 102: e12.

14. Rogé CLL, Silverman NH, Hart PA, Rauy RM. Cardiac structure growth pattern determined by echocardiography. Circulation 1978; 57: 285-90.

15. Mazzanti L, Prandstraller D, Tassinari D, et al. Heart disease in Turner's syndrome. Helv Paediat Acta 1988; 43: 25-31.

16. Coucineiro-Gianzo JA, Pérez-Cobeta R, Fuster-Siebert M, Barreiro-Conde J, Pombo-Arias M. Síndrome de Turner y alteraciones cardiovasculares. Anal Esp Pediatr 1996; 44: 242-4.

17. Grech V. Diagnostic and surgical trends, and epidemiology of coarctation of the aorta in a population-based study. Int J Cardiol 1999; 68: 197-202.

18. Van Meurs-van Woezik H, Klein HW, Krediet P. Normal internal calibres of ostia of great arteries and of isthmus in infants and children. Br Heart J 1977; 39: 860-5. 